\title{
ETUDE DE L'ACTIVITE ACAT DANS LES CELLULES HT29 DIFFERENCIEES ABSENCE DE CETTE ENZYME DANS LES CELLULES STANDARD INDIFFERENCIEES
}

lacombe C., Viallard $V$., Nebol $C$.

I.N.S.E.R.M. - Unité 317 , Institut de Physiologie, Rue Magendie 31400 Toulouse, France.

Nous avons étudié l'activité ACAT (Acyl CoA Cholestérol Acyl Transférase) sur différentes sous-populations provenant de la lignée HT29 (adénocarcinome colique) :

- les collules $\mathrm{G}^{+}$standard cultivées en présence de $25 \mathrm{mM}$ de glucose, indifférenciées;

- les cellules $\mathrm{G}^{-}$qui ont été sélectionnées à partir de la population standard et cultivées en absence de glucose;

- et ces mémes cellules $\mathrm{G}^{-}$cultivées en présence de glucose pendant plusieurs passages : cellules $\mathrm{G}^{-}$réversées.

Ces deux derniers modèles, qui présentent une différenciation de type entérocytaire, nous ont été fournis par l'Equipe de A. ZWEIBAUM (INSERM-U.178).

L'activité ACAT est similaire dans les deux modèles différenciés, $G^{-}$et $\mathrm{G}^{-}$réversées, elle est donc indépendante de la présence de glucose dans le milieu. Les caractéristiques de cette enzyme définies en présence d'oleyl CoA comme substrat sont $:$ Vmax $=50$ pmoles $/ \mathrm{mg} / \mathrm{min}$ et $\mathrm{Km}=13,9 \mu \mathrm{M}$. Le $\mathrm{Km}$ est proche de celui observé sur des microsomes de foie de rat (SYNOURI et MITROPOULOS; Eur. J. Biochem., 133, 299, 1983). L'ACAT est présente dès les premiers jours de culture mais son activité augmente au cours de la croissance. La valeur obtenue en phase stationnaire est comparable à celle observée sur des biopsies de cellules intestinales humaines $(60 \mathrm{pmoles} / \mathrm{mg} / \mathrm{min}$; NORUM et al., Eur. J. Clin. Invest., 9, 55, 1979).

Par contre. l'activité de cette enzyme n'est pratiquement pas détectable dans les cellules $\mathrm{G}^{+}$standard quel que soit le stade de croissance. Des études préliminaires montrent qu'elle n'est pas non plus stimulée par une préincubation en présence de cholestérol exogène (LDL et micelles). L'existence d'un taux de cholestérol membranaire plus élevé dans les cellules $\mathrm{G}^{+}$standard que dans les formes différenciées (résultats non publiés) pourrait ètre en relation avec leur défaut d'activité ACAT.

RELATION INVI:RSE ENTRE LA CONCENTRATION DES SERUMS FETAUX BOVINS EN HORMONE CHORIONIQUE SOMATUMAMMOTROPE ET LEUR AGE.

Beckers J.F., Woutcrs-Ballinan P., Ectors F.J., Touati K., Delval A., Bormans M. et Ectors F.

Dept. d'Endecrinologie et de Reproduction animale. Centre de recherche IRSIA. Faculté de Médecine Vétérinaire de l'Université de Liège. Rue des vétérinaires 45, B-1070 Bruxelles Belgique.

Au moment de développer un programme de culture d'embryons in vitro, nous nous sommes interrogés sur la composition des sérums foctaux, el en particulier sur leurs contaminations par des endotoxines, sur la présence des facteurs du complément et de coagulation, et enfin sur lcur tencur en hornone de croissance hypophysaire el placentairc conjoncturelement correlées aux somatomedines A ct C (IgF II et IgF I). Les sćrums foxtaux ont été recueillis à l'abatioir aussitôt après l'abattage des vaches. L'âge gestationncl cst đéterminé sclon la formule de Rexroad et al. (1974, J. Dairy Sci., 27 346), par une mesure de la longucur du foctus (de la nuque à la base de la queuc).

Les concentrations en hormone de croissance hypophysaire sont variabics d'un sérum a l'autre (40 a $100 \mathrm{ng} / \mathrm{ml}) \mathrm{et} \mathrm{ne} \mathrm{montrent} \mathrm{pas} \mathrm{de} \mathrm{profil}$ typique en fonction de l'àge gestationncl. Les concentrations en hormone placentaire sont élevées chez les fotus jeunes ( $\pm 25 \mathrm{ng} / \mathrm{ml}$ ); ensuite ciles décroissent régulièrement pour se situer à $\pm 5 \mathrm{ng} / \mathrm{ml}$ au moment de la naissance. Etant donné que l'hormone placentaire possçde une activité somatogénique spécifique 3 fois plus importante que l'hormone de croissance, que sa concentration est élevéce cn début de gestation et que ses effets se cumulent à ceux de l'hormone de croissance hypophysaire, les factus jeunes sont fortement imprégnés d'hormones de type somatogéniquc. Si, à unc époque détcrminée du développement ces concentrations élevées en hormones somatomammotropes sont corrélées avec des teneurs élevées en somatomédines et en facteurs de croissances, il scrait intéressant de ne retenir pour la culture que les sérums fọtaux prélevés en début de gestation. Ceci d'autant plus, que le sang de fatus jeunes cst bcaucoup moins riche cn leucocytes. en facteurs de coagulation et de complément. 